\title{
Molecularly imprinted polymers for sample preparation and biosensing in food
} analysis: Progress and perspectives

Ashley, Jon; Shahbazi, Mohammad-Ali; Kant, Krishna; Aaydha Chidambara, Vinayaka; Wolff, Anders; Bang, Dang Duong; Sun, Yi

\section{Published in:}

Biosensors and Bioelectronics

Link to article, DOI:

10.1016/j.bios.2017.01.018

Publication date:

2017

Document Version

Peer reviewed version

Link back to DTU Orbit

Citation (APA):

Ashley, J., Shahbazi, M-A., Kant, K., Aaydha Chidambara, V., Wolff, A., Bang, D. D., \& Sun, Y. (2017). Molecularly imprinted polymers for sample preparation and biosensing in food analysis: Progress and perspectives. Biosensors and Bioelectronics, 91, 606-615. https://doi.org/10.1016/j.bios.2017.01.018

\section{General rights}

Copyright and moral rights for the publications made accessible in the public portal are retained by the authors and/or other copyright owners and it is a condition of accessing publications that users recognise and abide by the legal requirements associated with these rights.

- Users may download and print one copy of any publication from the public portal for the purpose of private study or research.

- You may not further distribute the material or use it for any profit-making activity or commercial gain

- You may freely distribute the URL identifying the publication in the public portal 


\title{
Molecularly Imprinted Polymers for Sample Preparation and Biosensing in Food analysis: Progress and Perspectives
}

Jon Ashley ${ }^{\mathrm{a}}$, Mohammad-Ali Shahbazi ${ }^{\mathrm{a}}$, Krishna Kant ${ }^{\mathrm{a}}$, Vinayaka Aaydha Chidambara ${ }^{\mathrm{b}}$, Anders Wolff $^{\mathrm{a}}$, Dang Duong Bang ${ }^{\mathrm{b}}$, and Yi Sun ${ }^{\mathrm{a}}{ }^{*}$

${ }^{a}$ Department of Micro- and Nanotechnology, Technical University of Denmark, Ørsteds Plads, DK-2800 Kgs. Lyngby, Denmark.

${ }^{b}$ Laboratory of Applied Micro and Nanotechnology (LAMINATE), National Food Institute, Technical University of Denmark (DTU-Food), Denmark.

*Corresponding author.E-mail address:sun.yi@nanotech.dtu.dk

\begin{abstract}
Molecularly imprinted polymers (MIPs) are biomimetics which can selectively bind to analytes of interest. One of the most interesting areas where MIPs have shown the biggest potential is food analysis. MIPs have found use as sorbents in sample preparation attributed to the high selectivity and high loading capacity. MIPs have been intensively employed in classical solid-phase extraction and solid-phase microextraction. More recently, MIPs have been combined with magnetic bead extraction, which greatly simplifies sample handling procedures. Studies have consistently shown that MIPs can effectively minimise complex food matrix effects, and improve recoveries and detection limits. In addition to sample preparation, MIPs have also been viewed as promising alternatives to bio-receptors due to the inherent molecular recognition abilities and the high stability in harsh chemical and physical conditions. MIPs have been utilized as receptors in biosensing platforms such as electrochemical, optical and mass biosensors to detect various analytes in food. In this review, we will discuss the current state-of-the-art of MIP synthesis and applications in the context of food analysis. We will highlight the imprinting methods which are applicable for imprinting food templates, summarize the recent progress in using MIPs for preparing and
\end{abstract}


analysing food samples, and discuss the current limitations in the commercialisation of MIPs technology. Finally, future perspectives will be given.

Keywords: Molecularly Imprinted Polymers, Food Analysis, Biosensors, Sample Preparation 


\section{Introduction}

Foodborne poisoning and food intoxications have become major public concerns worldwide (Caballero et al., 2003). The residues of pesticides, veterinary and human drugs, microbial toxins, preservatives, as well as contaminants from food processing can cause apparent toxic effects and allergic reactions. Even at ultra-trace level, the contaminants can lead to cutaneous, respiratory, gastrointestinal or systemic response that may result in fatal anaphylactic shock. With the numerous reports on product recalls, food scares, and deliberate adulteration of food, stringent legislation has been continuously introduced, and testing of these contaminants is routinely performed.

In response to the demand for rapid, accurate and cost effective analytical methods to guarantee food safety, molecularly imprinted polymers (MIPs) as attractive materials have received immense attention. They can be tailor-made to bind template molecules with high selectivity (Chen et al., 2016). MIPs are synthesized by copolymerization of functional monomers and cross-linkers in the presence of template molecules. After removal of the template molecules, recognition cavities that are complementary in shape, size, and spatial arrangement to the template molecules are formed in the highly cross-linked polymer matrix.

Attributed to their unique features, MIPs have greatly advanced the field of food analysis (Song et al., 2014). MIP technology has been extensively applied in the area of sample preparation. Due to the complex food matrices effects and the trace presence of targeted analytes, the performance of the analytical instruments is highly dependent on the sample preparation. However, this is often a neglected area in assay development. As such, there is a need for researchers to develop good sample preparation techniques to compliment analysis of food samples. MIPs have found use as sorbents in sample preparation (Turiel and Martin- 
Esteban, 2010). Compared to conventional sorbents such as C18 silica gel, MIPs offer apparent advantages including higher loading capacities, higher efficiency for the retention of analytes and the improved selectivity during the retention process. Studies have consistently shown that the use of MIPs for food sample preparation could lead to improved recoveries and detection limits. Thus far, in majority of the examples, MIPs were employed in classical sample preparation techniques such as solid-phase extraction (SPE) and solid-phase microextraction (SPME) (Zhang et al., 2013). Recently, the use of MIPs in combination with magnetic bead extraction has significantly simplified sample handling and pre-treatment procedures, and opens up the opportunities to integrate sample preparation with emerging analytical devices such as biosensing/microfluidic platforms (Chen and Li, 2012).

Besides sample preparation, MIPs have also displayed great potential in area of biosensors (Uzun and Turner, 2016). Biosensors allow the miniaturization of instrumentation while demonstrating sensitivity and selectivity comparable to traditional analytical techniques (Otles and Yalcin, 2012). This is highly desirable in food monitoring as there is a demand for analytical methods which can be carried out at the point-of-need or anywhere else in the food processing chain. Biosensors rely on bio-receptors to recognize targeted analytes. Antibodies and enzymes have commonly been used as the receptors for biosensor platforms but they are inherently unstable due to the biological origins, which significantly limits the uptake of biosensors in the food sector. Recently, MIPs have been employed as biomimetic receptors in biosensing platforms. These MIPs provide a number of advantages over their biological counterparts, including high robustness and stability under a wide range of conditions, easy design of recognition sites for analytes that lack suitable bio-recognition elements, and low production cost. The advances in polymerization techniques have made it possible to directly fabricate MIPs on transducer surfaces, and the development of MIPs with multifunctional composites has enabled new mechanisms of signal transduction. Numerous MIP-based 
biosensors, such as electrochemical, quartz crystal microbalance (QCM), surface plasmon resonance (SPR), and optical biosensors, have been developed for diverse food relevant analytes ranging from small molecules to big proteins (Irshad et al., 2013).

Although the MIP technology is very promising for use in food analysis, the commercial success is still very limited. So far, there are only few commercial examples of MIPs as sorbents for sample preparation, and no MIP-based biosensors have yet been seen on the market. The commercialization of MIPs has been hampered by several challenges such as incomplete template removal, inadequate selectivity, as well as difficulties in producing MIPs on a large scale. To further prompt applications of MIPs in the food sector, efficient means of preparing MIPs should be developed in order to generate MIPs with significantly improved properties.

In this review, we mainly summarize the recent progress in regards to the development of MIPs in the area of food analysis over the last 5 years. Firstly, the current imprinting methods which are applicable to food templates will be reviewed. We will then compare and contrast the two main applications of MIPs in food analysis, namely, as sorbents in sample preparation and as receptors in biosensors. The limitations in the commercialisation of MIPs technology will also be discussed. Finally, perspectives on the future research directions will be provided.

\section{Molecular Imprinting Methods}

\subsection{Synthesis of MIPs}

MIPs can be synthesized using a number of different techniques. The main type of imprinting is non-covalent imprinting which relies on forming interactions between the functional monomer and templates in a pre-polymerization mixture (Figure 1). Strategies for non- 
covalent imprinting include bulk polymerization, precipitation polymerisation, mini emulsion polymerization, solid-phase imprinting, and core-shell imprinting (Song et al., 2014). Selection of imprinting method will depend on the size and form of the desired MIP (i.e., thin films, nanoparticles etc.), the type of template and application of the MIP to be used. For example, in food sample preparation, MIPs are often synthesized using the bulk polymerization method before they are grafted onto a solid phase support; whereas in MIPbased biosensors, thin films are most commonly grafted onto the sensor surface. For both applications, MIPs with high surface area and a large number of binding sites are desirable while non-specific binding should be kept to a minimum.

Bulk polymerization is one of the simplest imprinting methods, and involves the formation of large size MIP monoliths which can then be ground down into smaller irregular shaped microsphere particles. Due to the simplicity of the procedures, bulk polymerization is the most commonly used method in the development of MIP sorbents for sample extraction. However, the method can lead to high batch-to-batch variation and formation of particles with no binding sites (Chen et al., 2011; Ma et al., 2013). In addition, the technique requires a large amount of template, suffers from template leakage and is difficult to process.

More recently, the focus has been on the development of MIP nanoparticles (nano-MIPs) for both food sample preparation and biosensors due to the higher surface area-to-volume ratio and well-defined sizes (Wackerlig and Lieberzeit, 2015). Polymer chemists have used precipitation polymerization as a convenient method for imprinting of nanoparticles. It allows nanoparticles to be formed in reasonable yields, purity and with good control over particle sizes (Ye et al., 1999). The technique relies on mixing the template with a diluted solution of monomers and cross-linker, resulting in a high dilution factor. Upon formation, the MIP slowly precipitates out of the solution. Precipitation polymerization has allowed for 
imprinting of biomolecules such as proteins in the presence of a small amount of surfactant, but the technique is limited to high abundance templates (Hoshino et al., 2008).

Emulsion polymerization has proven to be a versatile method for preparing MIPs. The technique involves emulsifying the cross-linkers, template and functional monomers in an aqueous phase (Vaihinger et al., 2002). Stabilizers are then added to the disperse phase, which helps to prevent diffusion across the continuous phase and result in small, stabilised, homogeneous sized emulsion droplets. The method allows for high yields of monodispersed nanoparticles, whereas the surfactant residues can interfere with the recognition of the analyte upon rebinding, leading to low binding capacity.

Solid-phase based polymerization is an effective strategy for imprinting small molecules, endotoxins and even whole viruses. In this method, the template is attached to a solid support, usually in the form of glass beads or silica gel $(>1 \mu \mathrm{m}$ diameter), and mixed with the monomers, cross-linker and initiator before polymerizing using chemical or photo initiation (Abdin et al., 2015; Altintas et al., 2015a, 2015b). The technique offers some significant advantages over other methods for producing nano-MIPs (Canfarotta et al., 2016). These include the facile removal of the template which facilitates the recycling of the template for subsequent reactions. Moreover, the resultant nano-MIPs are monoclonal in nature meaning that only 1 or 2 recognition sites are formed per nanoparticle. The method can also be used as an affinity column which facilitates the separation of high affinity MIPs from the low affinity and non-imprinted by-products. In addition, a wide range of linker chemistries can be used to attach the template to the support. For instance, MIPs for trypsin were synthesized by attaching the protein via affinity capture with its inhibitor, glass bead templated paminobenzamidine (Ambrosini et al., 2013). This resulted in nano-MIPs, which were more uniform in terms of the orientation and size of the binding cavity. In a more recent paper, the same group demonstrated the use of a metal-chelates to bind His-tag containing proteins to 
glass beads (Xu et al., 2015). Solid-Phase imprinting does suffer from some disadvantages. There are only a limited number of solid supports available with the technique being demonstrated on glass beads and silica gels. This is partly due to the large amount of beads required (>30 g). Moreover, in the solid-phase approach, low affinity MIPs are removed while high affinity MIPs are retained, which often results in a much lower yield.

Surface imprinting can be considered as a form of solid-phase imprinting which involves the formation of a layer of MIP round a solid medium such as nanoparticle or glass slide. There has been intense research activity focusing on core-shell imprinting, since it allows for better control of both the size and distribution of the MIP and the functionality of the nanoparticle. The large surface area of the nanoparticles allows for fast MIP binding kinetics and increases the access of the analyte to the MIP. In addition, the aggregation of nanoparticles can be minimised through the addition of a shell layer or other surface modification (Gawande et al., 2015). Moreover, the core of the imprinted nanoparticle can consist of any number of precursor nanoparticles such as iron oxide (magnetite), silicon oxide, quantum dots or polymers themselves, which could impose additional functions to MIP nanoparticles.

The first core-shell imprinting method was reported by Pérez-Moral et al., where a MIP was imprinted onto a polymer based core through surface initiated living radical polymerization (Pérez-Moral and Mayes, 2007). Recently researchers used the grafting approach to produce magnetic core-shell MIP nanoparticles. Magnetic nanoparticles were synthesized using coprecipitation of iron chloride which resulted in magnetic core nanoparticles. This was followed by the formation of a $\mathrm{SiO}_{2}$ shell layer via silanization using tetra ethyl orthosilicate (TEOS). The MIP layer was then grafted onto the core-shell to bind biotin (UzuriagaSanchez et al., 2016). There has been an increasing interest in using molecularly imprinted magnetic core-shell nanoparticles for effective sample extraction due to the facile removal of these nanoparticles from food matrices. Quantum dots have also been commonly used as the 
core for molecular imprinting which effectively turns them into fluorescence-based sensors (Liu et al., 2012, 2016). Other types of core nanoparticle used for imprinting include silver and gold nanoparticles. Silica based MIPs with a core comprised of silver nanoparticles were developed, which took advantage of the unique optical properties known as metal enhanced fluorescence exhibited by silver nanoparticles (Aguilar-García et al., 2016). Gold nanoparticles can also act as the core for imprinting MIPs due to their unique UV absorbance properties (Yu et al., 2012). Core-shell imprinted polymers which incorporate multiple functional materials have shown potential by combining the unique properties of multiple nanoparticle systems. In 2014, Han et al. developed hybrid $\mathrm{Fe}_{3} \mathrm{O}_{4}-\mathrm{CdTe}$ quantum dot coreshell imprinted nanoparticles which could recognise and bind to 4-nonylphenol (Han et al., 2014). Hollow shell imprinting, where the core of the particle is removed after imprinting, has been of interest to the scientific community. A recent paper used a one pot sol-gel process to synthesise the $\mathrm{SiO}_{2}$ core (C. Li et al., 2015a). After immobilization of the template, surface imprinting and addition of a poly(N-isopropylacrylamide)-block-poly(2hydroxyethyl methacrylate) brush, the core was removed through etching with $10 \%$ hydrofluoric acid (HF). Although the development of core-shell imprinting is a promising area, there are still improvements to be made such as minimising the degree of nanoparticle aggregation, and further enhancements in controlling the size and size distribution of the nanoparticles.

Methods for imprinting thin films have been the focus of a number of groups, and are highly desirable in biosensors such as electrochemical sensors where the surfaces can be fabricated using methods such as electro-polymerization. In situ electro-polymerization is a special form of surface imprinting onto the electrode (Suryanarayanan et al., 2010). A significant advantage of this approach is that the technique allows the thickness of the polymer to be precisely controlled by various parameters such as current density and applied voltage, which 
gives rise to a more uniform coating of the MIP onto the electrode surface (Malitesta et al., 2012; Pardieu et al., 2009). Moreover, the area of deposition of the polymer can also be well controlled. Non-conducting imprinted polymers can be integrated with an electrochemical transducer by in situ electro-polymerization of monomers in the presence of aniline or ethylenedioxythiophene. Alternatively, the imprinted polymers can be immobilised on the surface of the electrode by either spin coating or electrospraying. Other forms of imprinted polymer such as nanoparticles can be attached via mixing with gels, membranes, carbon electrode paste and ink casting (Sharma et al., 2012).

\subsection{Design of MIPs}

The development of MIPs for new templates is often time consuming and requires a trial-anderror approach. There are several experimental parameters that need to be considered in terms of the type and concentration of monomers, cross-linker and template. The temperature at which the polymerization is carried out is also an important factor to consider when temperature responsive monomers or temperature sensitive templates are used. Several methods for designing MIPs have been reported, including chemometric, molecular modelling, combinatorial approaches and experimental methods (Curk et al., 2016).

Chemometric based design approaches have been demonstrated on a number of different templates. It relies on statistical analysis which allows MIPs to be designed based on experimental data (Muzyka et al., 2014).

Recently, molecular modelling has become an increasingly popular method for the rational design of MIPs through modelling of critical imprinting parameters (Nicholls et al., 2015). For example, a model combining Monte Carlo simulations and analytical calculations was proposed as a method for the rational design MIPs (Curk et al., 2015). Virtual combinatorial screening of various monomers towards Benzo[ $\alpha]$ pyrene in pre-polymerization mixtures was 
demonstrated using a semi empirical quantum method. The binding energy was computed using the Hartree Fock method resulting in the selection of methacrylic acid as the monomer and ethylene glycol dimethyacrylate as the cross-linker for imprinting (Khan et al., 2012). Hawari et al. used 3D simulation to assess the binding of a series of monomers towards $\alpha$ pinene, a volatile compound given off upon ripening of mangos (Hawari et al., 2013). The use of computational chemistry in the design of MIPs has shown promise in terms of facilitating the rapid development of MIPs with a reduction of the amount of reagents needed. However, the effective modelling of larger macromolecules remains a challenge. One of the few examples of macromolecule MIP modelling was reported in 2011, when researchers used molecular docking as a strategy to simulate macromolecule-monomer interactions (Kryscio et al., 2011).

The use of combinatorial libraries to rapidly screen MIP candidates for high affinity towards the template was first developed in 1998 using different triazine herbicides as the templates (Toshifumi Takeuchi et al., 1998). In 2007 Koesdjojo et al. developed a semi-automated procedure for the synthesis and screening of MIPs using drug residues as the template (Koesdjojo et al., 2007). Researchers in 2012, combined microfluidic technology with combinatorial chemistry to develop MIP microspheres for Chloramphenicol with good control over the size of the resultant microspheres (Liu and Lei, 2012). These procedures allowed the researchers to quickly optimise monomer ratios and other critical parameters such as the porogen used. The procedure reduced the consumption of reagents and demonstrated the possibility of small scale high throughput polymerization. However to date there has only been a small number of publications on the development of combinatorial based approaches for MIP synthesis.

Experimental method is another approach for rational design of MIPs. Previous reports have shown that the design of MIPs for small molecules based on experimental analysis of pre- 
polymerization mixtures using techniques such as nuclear magnetic resonance (NMR) (Salvador et al., 2007). A recent article demonstrated the use of differential scanning fluorimetry in the development of MIP-NPs for the milk protein allergen $\beta$-lactoglobulin (Ashley et al., 2016). The method relies on the use of a hydrophobic dye and real time PCR thermocycler to determine the optimum conditions for imprinting, characterise the formation of the MIP-NPs and potentially allow for the binding between the MIP and protein to be assessed.

\section{Applications of MIPs in food sample preparation}

Sample preparation is one of the major bottlenecks of the analytical process in food analysis because of the complex food matrices effects and the low concentration of target analytes. Efforts have recently been made towards developing more selective sample extraction methods. MIPs have been extensively suggested and used as sorbents for sample preparation. The main advantage of MIPs is that they can concentrate the analyte and selectively extract the target compound from bulk samples. They can avoid the problem of non-specific affinity associated with conventional sorbents such as $\mathrm{C} 18$-bonded silica gel, thereby allowing for more sensitive and selective quantification. Moreover, MIPs are also advantageous in terms of high sample load capacity, appropriate resistance to high temperature and pressure (high stability), desirable physical robustness, inertness to organic solvents as well as acids and bases, ease of preparation and low cost (Carro-Diaz and Lorenzo-Ferreira, 2010; He et al., 2007; Lasáková and Jandera, 2009). MIPs have mainly been employed in classical sample preparation methods such as SPE and SPME. More recently, the development of magnetic MIP nanoparticles has allowed MIPs to be combined with magnetic bead extraction, which greatly simplifies sample handling procedures. 


\subsection{MIP-based SPE}

MIP-based SPE is the most popular method for preparing food samples because it is convenient, fast, consume less solvent and enable selective cleanup of the analytes. In a typical MIP-SPE, imprinted bulk polymer is packed in a cartridge, column, or extraction well plates (for high throughput analysis). Recently, alternative forms of MIPs such as thin films and nanoparticles are also used as sorbents in SPE.

Two different approaches have been considered for extraction of analytes by MIPs, namely "normal phase" mode used for processing food samples dissolved in low polarity solvent and "reverse phase" mode for aqueous food samples. In "normal phase" mode, the adsorption of the analytes onto an MIP sorbent is via shape-specific interactions of the analytes with the polymer matrix. The analyte is selectively retained on the extraction column while interfering molecules can freely pass through the column. Increasing the mobile phase strength will result in the elution of the analyte. In contrast, in the "reverse phase" mode, analytes in aqueous samples are adsorbed onto the MIP through hydrophobic interactions. Subsequent washing with solvent can remove interfering compounds leaving the analyte. The elution of the analyte can occur when the column is washed with appropriate solvent. The solvent used for washing should be able to minimize non-specific binding while having no disruptive effect on the selective interactions between the target molecules in food samples and the MIP (Andrade-Eiroa et al., 2015; Anene et al., 2016; Atlabachew et al., 2016). Clean-up using washing solvents can be skipped in special cases where the elution step is highly selective to the analyte and does not elute other reagents non-specifically bound to the MIP. This is recommended especially for aqueous samples where the clean-up step by non-polar solvent may give rise to miscibility issues (Lasáková and Jandera, 2009). 
There are several reports in the literature showing the application of MIP-SPE in extracting antibiotics, pesticides, and mycotoxins from food samples (Baggiani et al., 2007; Cacho et al., 2003; Chauhan et al., 2016; Chen et al., 2009; Muzyka et al., 2014b; Khan et al., 2016; Molinelli et al., 2002). By enhancing selectivity, MIP-SPE has been demonstrated to be superior compared to traditional SPEs. For example, the detection of fluoroquinolones in baby food was successfully achieved (limit of detection (LOD) of 0.03 to $0.11 \mu \mathrm{g} \cdot \mathrm{g}^{-1}$ ) after loading the samples onto bulk imprinted polymer (Díaz-Alvarez et al., 2009). Besides MIPs made by bulk polymerization, nano-based core-shell type molecularly imprinted sorbents were also utilized for food analysis. For example, Wang et al. (Xiaoyan Wang et al., 2014) were able to extract estradiol from milk samples using core-shell molecularly imprinted hollow spheres.

Previously, it was difficult for SPE to analyze several analytes at the same time (Lejeune and Spivak, 2009; Schweitz et al., 2002). Zhang et al. overcame the challenge of multi-analyte analysis in SPE by developing novel multiple-template MIPs (MT-MIP) (Zhang et al., 2015). The MT-MIP was synthesized by dispersion polymerization, using ofloxacin and $17 \beta$ estradiol as templates and modified monodispersed poly(glycidylmethacrylate-co-ethylene dimethacrylate) ( $\left.\mathrm{P}_{\mathrm{GMA} / \mathrm{EDMA}}\right)$ beads as the support material. The MT-MIP could simultaneously extract trace quinolones and estrogens in milk samples with the recoveries in the range of $77.6-98.0 \%$.

\subsection{MIP-based SPME}

SPME is a sample preparation method which uses a syringe with a needle containing stainless steel microtubing and fused-silica fiber tips coated with an organic polymer (Arthur and Pawliszyn, 1990). This coated silica fiber is capable of moving forwards and backwards with 
the syringe plunger. The unique design of SPME provides advantages such as reduced time for sample preparation, non-usage of organic solvents, low cost, and ease of automation (Vas and Vékey, 2004; Zhang et al., 2013). However, the main drawback associated with SPME is the lack of selectivity, the same as traditional SPE.

By coating the fiber tips with MIPs, SPME has demonstrated superior sensitivity and selectivity. For example, MIP-coated stainless-steel fibers were developed to extract a Sudan (I-IV) carcinogen dyes in hot poultry and chili powder samples. The sensitivity of the method was very high, being able to achieve LODs of $2.5-4.6 \mathrm{ng} / \mathrm{g}$ for Sudan I-IV dyes (Hu et al., 2012).

One of the most interesting ideas recently appeared is the combination of MIP and sol-gel technologies to produce water-compatible MIP based extraction systems (C. Li et al., 2015b; Wang et al., 2013). For example, Wang et al. reported sol-gel coating of MIP while using polyethylene glycol as functional monomer and diazinon as template (Wang et al., 2013). The authors were able to show selective detection of diazinon and its analogs in cabbage, eggplant, green pepper, cucumber, and lettuce samples. In addition to outstanding chemical and thermal stability, the extraction capability was higher than commercial fibers and nonimprinted polymer due to selective adsorption and the highly porous surface.

Temperature sensitive MIPs coupled to SPME has recently been demonstrated by Zhao et al. (Zhao et al., 2015). They were able to successfully extract ofloxacin (OFL) from milk and analyse it using HPLC coupled to MIP coated SPME. In addition to temperature sensitive MIPs, new molecularly imprinted SPME fibers with the ability to renew their selective binding sites through the gradual thermal decomposition of the polymeric network were reported (Xu et al., 2016). In the desorption step, the polymeric network can degrade from the 
surface to the core in the presence of volatile compounds that do not cause any interference with the analyte. High precision and accuracy were observed for the successful extraction of triazole fungicides, such as triadimenol, tebuconazole, and metconazole from grape juice samples using this renewable MIP fiber (Pozo-Bayón et al., 2001; Sabik et al., 2012).

In addition to the above-mentioned examples, some of the most interesting work in MIPbased SPE and SPME is summarized in Table 1.

\subsection{Magnetic MIP nanoparticle-based extraction}

Recently, another sample preparation method based on magnetic MIP nanoparticles has received considerable attention. The magnetic MIPs typically consist of a magnetic core and a MIP layer at the shell, thus they possess both magnetically susceptible characteristics and good selectivity for the target molecules (Figure 2). In the separation procedure, the magnetic MIP sorbents can be dispersed directly in food samples to extract analytes. The nanoparticles together with captured analytes are then recovered from the solution with the aid of a magnet. The combination of magnetic nanoparticles with MIP technology has proven to be a powerful method for sample pre-treatment and enrichment attributed to the effective analyte-sorbent interaction and facile separation from the sample matrices (Chen and Li, 2012).

Magnetic MIP nanoparticle-based extraction has been increasingly used for concentrating food contaminants such as pesticides, herbicides, endocrine disrupting chemicals, antibiotics, and growth hormones in complex sample matrices that include milk, fruit juices, honey, egg and meat products (Chen and Li, 2012b, Kwasniewska et al., 2015). The sample recoveries shown by magnetic MIPs were between $75 \%$ and $95 \%$ on average for various contaminants. 
Chen et al. revealed that magnetic MIP nanoparticle-based extraction was superior over the MIP-SPME and MIP-SPE methods (Chen et al., 2009). They compared the performance of the three methods for separation of tetracycline and oxytetracycline antibiotics from egg and tissue samples. The magnetic MIP method showed better analytical results with a detection limit of $0.06-0.19 \mathrm{ng} \mathrm{g}^{-1}$ and a recovery rate of $72.8-96.5 \%$, while the recovery rates for MIP-SPME and MIP-SPE were $71.6-93.7 \%$ and $66-69 \%$, respectively. In addition, the sample preparation time used in the magnetic MIP method was much shorter since the extraction and clean-up were easily done by separating the magnetic polymers from the sample matrix.

A recent paper demonstrated the use of magnetic MIP nanoparticles to extract 1,7-dioxaspiro[5,5]-undecane (DSU), a potential biomarker for infected olive oil caused by olive fruit flies (del Carmen Alcudia-León et al., 2016). The magnetic MIPs were prepared using 3aminopropyltriethoxysilane (APTES) to associate the target analyte on the surface of the magnetic substrate, followed by the polymerization of ethylene glycol dimethacrylate (EGDMA). The simple methodology showed remarkable recovery rate ranging between 95 and $99 \%$.

Novel magnetic hollow nanoparticles, where the core of the nanoparticle undergoes etching, have been used for highly selective recognition and fast enrichment of triazines in food samples (Wang et al., 2016). The magnetic hollow MIPs were prepared using multi-step swelling polymerization, followed by in situ growth of magnetic nanoparticles on the surface of hollow MIPs. They were applied to extract atrazine, simazine, propazine, and terbuthylazine in corn, wheat, and soybean samples. Satisfactory recoveries in the range of $80.62-101.69 \%$ were obtained. 
Magnetic MIP nanoparticle-based extraction technique surpasses most of the classical sample preparation procedures with simpler operation and higher adsorption capacity. The technique significantly simplifies the sample handling and pre-treatment protocols. Up to date, sample preparation is widely recognized as the critical roadblock in realizing online or at-site food contaminant analysis. Emerging microfluidic technology that enables the integration of sample preparation and biosensing in one portable system could offer a promising solution. Magnetic beads have been explored for on-chip sample preparation (Bunyakul and Baeumner, 2015). The possible combination of magnetic MIPs with microfluidic platforms would open up new opportunities for online analysis of trace compounds in complex food sample matrices.

\section{MIP-based biosensors in food analysis}

Besides being used as adsorbents for sample preparation, more recently, MIPs have been increasingly applied in sensing technology. Over the past few decades, the food industry is actively seeking novel sensing platforms that can be employed at point of use. The development of biosensors has improved the overall capabilities to detect chemical and biological molecules. However, applications of biosensors in the real world are greatly hindered by the limited operational and storage stability of the bio-receptors. With the inherent molecular recognition abilities and high stability in harsh chemical and physical conditions, MIPs have been recognized as a promising alternative to bio-receptors.

The advances in MIP synthesis technologies have greatly propelled the development of MIPbased biosensors. New polymerization methods have allowed the MIP materials to be immobilized on transducer surfaces, and novel multi-functional MIP nanoparticles have also 
contributed to transform the binding events into measurable signals. Examples of MIP-based biosensors include electrochemical, QCM, SPR and optical sensors (Cieplak and Kutner et al., 2016). They have shown great potential in the area of food and environmental monitoring, as they are cost-effective, fast and potentially portable. A schematic diagram of MIP based biosensors is shown in Figure 3 and some recent examples of MIPs used as selective recognition elements in a broad range of transducer types are summarised in Table 2.

\subsection{Electrochemical sensors}

MIP electrochemical sensors based on voltammetry/amperometric, conductivity and potentiometric transduction modes have been reported in the literature (Suryanarayanan et al., 2010). Many MIP electrochemical sensors incorporate conducting monomers into the MIP to allow for signal transduction (Malitesta et al., 2012). A change in signal can be induced upon direct binding of the analyte, or via competitive displacement measurements. To enable signal transduction, the MIP receptor needs to be in close proximity to the transducer surface, and this can be achieved either by in situ electro-polymerization of the monomers and crosslinkers or by coating a preformed polymer on the transducer surface. The majority of papers on MIP-based electrochemical sensors in food analysis deal with the detection of small analytes, while only a small portion of work target larger biomolecules.

MIP based potentiometric biosensors have displayed advantages over other electrochemical techniques such as simple design and good selectivity. In addition, the potentiometric sensor does not require dispersion of the template throughout the membrane on the electrode (Weng et al., 2007). Anirudhan et al. demonstrated the use of multi carbon walled carbon nanotubes with MIPs to develop potentiometric based sensor for the detection of monosodium glutamate in different food samples with a sensitivity of as low as $1 \mathrm{nmol} \mathrm{L}{ }^{-1}$ (Anirudhan and Alexander, 2015). 
MIP based amperometric electrochemical sensors have shown promise in food analysis with several publications in the literature (Zhao et al., 2013; Li et al., 2012; Farre and Barcelo, 2007). They rely on the relationship between the analyte concentration and the current density at a constant potential. A recent paper demonstrated the use of an electrochemical biosensor for the detection of sulfadimethoxine in milk samples using amperometric analysis (Turco et al., 2015). The MIP was deposited on the gold electrode via galvanostatic deposition of pyrrole in the presence of the template. The sensor achieved a detection limit of $70 \mu \mathrm{mol} \mathrm{L} \mathrm{L}^{-1}$.

MIP-based voltammetric biosensors measure the current density produced from potential sweep. The potential sweep can be produced by either linear sweep voltammetry (LSV), cyclic voltammetry (CV), differential pulse voltammetry (DPW) and square wave voltammetry (SWV) modes. In 2015 Deng et al developed a highly sensitive and selective MIP electrochemical sensor using square wave voltammetry to detect melamine in milk samples (Deng et al., 2015). The MIP was fabricated by electro polymerisation onto a glassy carbon electrode and could detect melamine with a detection limit of $1.4 \mathrm{nmol} \mathrm{L}{ }^{-1}$.

Although impedance is not strictly counted as an electrochemical technique, the fundamental basis for the technique is similar to other electrochemical methods. A recent example of an impedance based biosensor was developed by Yang et al. in which a hybrid of MIP carbon nanotubes and graphene was fabricated on a glassy carbon tube. It was capable of measuring rutin in buck wheat tea and orange juice samples with a detection limit of $5 \mathrm{nmol} \mathrm{L}{ }^{-1}$ (Yang et al., 2016).

\subsection{Piezoelectric biosensors}

MIPs have also been utilized in quartz crystal microbalance (QCM) biosensors which are based on the piezoelectric effect. This type of biosensors is most suitable for large analytes 
since they can induce big mass difference and consequently a large signal change upon binding. QCM uses a thin disc of quartz, which is cut at a specific crystal plane and inserted between a pair of gold electrodes as the transducer. QCM sensor can exhibit superior sensitivity down to the picomolar range. QCM provides a flexible technique to determine protein analyte concentration by measuring variations of the mass and physicochemical properties of the polymer sensing surface (Harz et al., 2011). Eren et al. developed a MIPQCM biosensor for the detection of lovastatin in red yeast rice, and detection limit of $30 \mathrm{pM}$ after extraction using Trichloroacetic acid was achieved (Eren et al., 2015). The sensor was fabricated by attaching a polymerizable self-assembly monolayer (SAM) to the gold surface via a thiol bond and imprinting lovastatin using free radical polymerization. In 2014, Dai et al. developed a MIP based QCM biosensor for the detection of histamine in tuna food samples, which obtained a LOD of $7.49 \times 10^{-4} \mathrm{mg} \mathrm{kg}^{-1}$ (Dai et al., 2014). The sensor was fabricated by molecularly imprinting histamine using TEOS and 3mercaptopropyltriethoxysilane, and the subsequent MIP was immobilised onto the gold surface using PVC in dichloromethane. The sensor displayed excellent sensitivity compared to HPLC for spiked fish samples after homogenization and extraction in h-hexane. MIP based QCM sensors also provide the possibility for high-throughput analysis as demonstrated by researchers in 2010. They developed a QCM array for the detection of six different herbs using polystyrene based MIP membranes which were fabricated by spin coating layers onto the surface (Iqbal et al., 2010).

One of the main challenges to develop MIP-based QCM biosensors is the complexity in fabricating the sensor surface. Chemistries used to attach the MIP or form it on the surface of the sensor must be compatible with gold or the self-assembly monolayer. As this technique cannot distinguish between specific and non-specific interactions (i.e. the interaction of the 
analytes with the sensor surface rather than the MIP), there is a need to both reduce nonspecific interactions and incorporate the non-imprinted polymer as a reference channel.

\subsection{SPR biosensors}

SPR is also considered as a mass sensitive technique. MIPs have proven to be effective receptors in SPR sensors. Methods to fabricate these types of biosensors include surface initiated atom radical polymerization (ATRP), amine coupling of MIP nanoparticles, photopolymerization of films using water compatible cross-linker and monomers, and amine coupling of MIP-NPs (Altintas et al., 2016; Jing et al., 2016; N. Zhao et al., 2012).

A number of MIP-based SPR biosensors for detection of food analytes have been reported in the literature (Lautner et al., 2011; Matsui et al., 2009). Yao et al. reported the use of a MIP based SPR sensor for the detection of pesticide residues (Yao et al., 2013). By combining SPR detection with MIP functionalised iron oxide nanoparticles, the magnetic iron oxide nanoparticles could serve a dual role of extracting the analyte from the sample while also acting to amplify the SPR signal. This increase in signal gave rise to a detection limit of 0.76 nM. The same group went on to develop novel nano-hybrid MIP based biosensor for the detection of ractopamine which incorporated both gold nanoparticles and reduced graphene oxide (Yao et al., 2016). The sensor was capable of measuring ractopamine down to $5 \mathrm{ng} /$ $\mathrm{ml}$.

\subsection{Optical Biosensors}

Optical based biosensors are particularly desirable in food analysis due to their high sensitivity (Narsaiah et al., 2012). Colorimetric biosensors are the simplest type of optical sensors which offer label-free detection based on changes in colour. Colorimetric detection was combined with MIP technology in 2012 to detect the food additive vanillin (Peng et al., 
2012). A change in the colour was induced when the photonic hydrogels bound to the analyte.

MIP based fluorescence sensors are also known for their rapid and sensitive measurements in solution. Composite nanomaterials which combine quantum dot labels and MIPs as the recognition layer have been developed for an array of food contaminants such as polycyclic aromatic hydrocarbons, proteins, and penicillin in food samples (Benito-Peña et al., 2006; Ge et al., 2013; Li et al., 2013; Lin et al., 2004). In 2012, Zhao et al. developed multi-functional QD-MIP nanospheres for the detection of pesticides in aqueous solutions (Y. Zhao et al., 2012). Upon recognition and binding of the analytes, there was a marked increase in fluorescence quenching which allowed for the quantitative measurement of diazinon concentration down to $36 \mathrm{ng} \mathrm{ml}^{-1}$.

The development of surface enhanced Raman spectroscopy (SERS) biosensors has generated huge interest in the research community due to their high sensitivity and ability to perform multiplex detection (Bantz et al., 2011; Rodriguez-Lorenzo et al., 2012). In food analysis, several papers have described the use of these types of sensors with MIP receptors (Feng et al., 2017; Feng and Lu, 2015). In 2013, bisphenol A molecularly imprinted gold nanoparticles were made as the substrate for a SERS biosensor which was capable of detecting bisphenol $\mathrm{A}$ in beverages with a detection limit of $0.12 \mathrm{mg} \mathrm{L}^{-1}$ (Xue et al., 2013). Recent applications of SERS biosensors with MIP receptor include the detection of melamine in milk, Sudan 1 in paprika and histamine in tuna samples (Gao et al., 2015a, 2015b; Hu and Lu, 2016).

\section{Challenges of MIPs in food analysis}

Despite the rapidly expanding literature on the use of MIPs in food analysis, the commercial exploitation of MIPs is still in its infancy. There are very few commercial products which use 
MIPs as sorbents for sample preparation. For example, SupeIMIPTM from Sigma Aldrich utilises MIPs in its solid phase extraction cartridges for the extraction of aminoglycosides from pork samples and mycotoxin from fruit samples (Sigma-Aldrich, 2016). Biotage offers customisable MIP technology for solid phase extraction (Biotage, 2016). In contrast to the commercialisation of MIPs in the area of sample preparation, there are no known commercial examples of MIP-based biosensors in food analysis.

The applications of MIPs have been hampered by several issues. For MIP-based sample preparation, the challenges include incomplete removal of template, non-specific binding due to the low yields of specific anchoring sites, as well as undesired adsorption due to the hydrophobic nature of many MIPs. The inability to completely remove the residual templates from the column matrix can result in its residual leakage during sample loading, washing operation, and more critical in elution steps (Baggiani et al., 2007; He et al., 2007). The presence of non-selective binding sites in MIPs may lead to the co-extraction of undesired matrix components, which could severely interfere with the quantification of molecule of interest in complex matrices. Problems with non-specific adsorption to polymer surface are often encountered for many hydrophobic MIPs. If the majority of binding events occur through adsorption to the polymer surface, the selectivity associated with the imprinted sites may remain obscured.

For MIP-based biosensors, the lack of commercial products is partly due to the unmet selectivity and binding affinity required for an effective biosensor. Limited by template quality and synthetic conditions, it is generally difficult for MIPs to achieve selectivity comparable to natural bio-receptors. Another challenge lies in the complexity in fabricating MIPs on sensor surfaces. This is especially true when multiple channels are involved such as in SPR, QCM based sensors which require both reference channels and analyte channels. Although a number of methods are available for construction of MIP-based biosensors, 
transferring these methods from research laboratories to industrial scale production remains a significant challenge.

\section{Conclusions and future perspectives}

In this review, preparation methods for MIPs and their applications for sample preparation and biosensing in food analysis has been comprehensively summarized. There is no doubt that the use of MIPs in food analysis will grow at an even faster pace. The future research may focus on the following areas.

1. Efficient means of preparing MIPs. In order for MIPs to take their place in analytical market, novel imprinting techniques are urgently needed to generate imprinting materials with high capacity, selectivity and homogeneity of binding affinity. This would be beneficial for both sample preparation and biosensing. In addition, large scale synthesis routes should be explored to facilitate industrialization of MIP products.

2. Rational design of MIP materials. The development of MIP-based products demands further progress on the understanding of molecular imprinting technology. Rational design approaches such as molecular modelling would aid the design and efficient selection of new functional and cross-linker monomers, thereby shortening the development time and expedite the synthesis process. This is extremely useful when imprinting MIPs for templates where their production is challenging and costly.

3. Development of MIPs for macrobiomolecules. So far most imprinting targets are small molecules, such as herbicides, additives, and metal ions. However, bacteria or large proteins such as toxins and hormones are also important targets in food analysis. The development of tailor-made MIPs for the detection of bacteria and proteins in aqueous solutions will be one important research direction. 
4. Development of more advanced and functional materials. The exploitation of new monomers with responsive functionalities and the introduction of new polymerization techniques would result in the development of novel sensor devices for different food analytes.

5. Incorporation of MIPs into microfluidic devices. With the recent development of microsystems, lab-on-a-chip technology and microfluidics have been utilized as a powerful tool where different analytical steps can be integrated on a single device. Taking the advantage of the fact that MIPs are fully compatible with lab-on-a-chip and nanotechnology, it is possible to use MIPs for both sample preparation and detection on the same microfluidic platform. Such an integrated device can allow for on-site and fast detection, which would be a big breakthrough in food analysis.

\section{Acknowledgements}

This work was financially supported by the Villum Fonden, Denmark, project No. 13153, and the European Union's Horizon 2020 research and innovation program, grant agreement No. 687697.

\section{References}

Abdin, M.J., Altintas, Z., Tothill, I.E., 2015. Biosens. Bioelectron. 67, 177-183. doi:10.1016/j.bios.2014.08.009

Aguilar-García, D., Ochoa-Terán, A., Paraguay-Delgado, F., Díaz-García, M.E., Pina-Luis, G., 2016. J. Mater. Sci. 51, 5651-5663. doi:10.1007/s10853-016-9867-X

Altintas, Z., Abdin, M.J., Tothill, A.M., Karim, K., Tothill, I.E., 2016. Analytica Chimica Acta Anal. Chim. Acta 935, 239-248. doi:10.1016/j.aca.2016.06.013

Altintas, Z., Gittens, M., Guerreiro, A., Thompson, K.-A., Walker, J., Piletsky, S., Tothill, I.E., 2015a. Anal. Chem. 87, 6801-7. doi:10.1021/acs.analchem.5b00989

Altintas, Z., Guerreiro, A., Piletsky, S.A., Tothill, I.E., 2015b. Sensors Actuators, B Chem. 213, 305-313. doi:10.1016/j.snb.2015.02.043 
Ambrosini, S., Beyazit, S., Haupt, K., Tse Sum Bui, B., 2013. Chem. Commun. 49, 67466748. doi:10.1039/c3cc41701h

Andrade-Eiroa, A., Canle, M., Leroy-Cancellieri, V., Cerdà, V., 2015. TrAC Trends Anal. Chem. 80, 655-667. doi:http://dx.doi.org/10.1016/j.trac.2015.08.014

Anene, A., Hosni, K., Chevalier, Y., Kalfat, R., Hbaieb, S., 2016. Food Control 70, 90-95. doi:http://dx.doi.org/10.1016/j.trac.2015.08.014

Anirudhan, T.S., Alexander, S., 2015. RSC Adv. 5, 96840-96850. doi:10.1039/C5RA17885A

Arthur, C.L., Pawliszyn, J., 1990. Anal. Chem. 62, 2145-2148. doi:http://dx.doi.org/10.1021/ac00218a019

Ashley, J., Shukor, Y., Tothill, S., 2016. Analyst 1-28. doi:10.1039/C6AN01155A

Atlabachew, M., Torto, N., Chandravanshi, B.S., Redi-Abshiro, M., Chigome, S., Mothibedi, K., Combrinck, S., 2016. Biomed. Chromatogr. 30, 1007-15. doi:10.1002/bmc.3643

Baggiani, C., Anfossi, L., Giovannoli, C., 2007. Anal. Chim. Acta 591, 29-39. doi:http://dx.doi.org/10.1016/j.aca.2007.01.056

Bantz, K.C., Meyer, A.F., Wittenberg, N.J., Im, H., Kurtuluş, O., Lee, S.H., Lindquist, N.C., Oh, S.-H., Haynes, C.L., 2011. Phys. Chem. Chem. Phys. 13, 11551-67. doi:10.1039/c0cp01841d

Benito-Peña, E., Moreno-Bondi, M.C., Aparicio, S., Orellana, G., Cederfur, J., Kempe, M., 2006. Anal. Chem. 78, 2019-2027. doi:10.1021/ac051939b

Biotage, 2016. Biotage - MIPs - Molecularly Imprinted Polymers [WWW Document]. URL http://www.biotage.com/product-page/mips---molecularly-imprinted-polymers

Bunyakul, N., Baeumner, A.J., 2015. Sensors (Basel). 15, 547-564. doi:10.3390/s150100547

Caballero, B., Trugo, L., Finglas, P.M., 2003. Encyclopedia of Food Science and Nutrition. Wiley.

Cacho, C., Turiel, E., Martín-Esteban, A., Pérez-Conde, C., Cámara, C., 2003. Anal. Bioanal. Chem. 376, 491-6. doi:10.1007/s00216-003-1915-0

Canfarotta, F., Poma, A., Guerreiro, A., Piletsky, S., 2016. Nat. Protoc. 11, 443-55. doi:10.1038/nprot.2016.030

Carro-Diaz, A.M., Lorenzo-Ferreira, R.A., 2010. Anal. Chim. Acta 668, 87-99. doi:10.1016/j.aca.2010.04.019

Chauhan, R., Singh, J., Sachdev, T., Basu, T., Malhotra, B.D., 2016. Biosens. Bioelectron. 81, 532-545. doi:10.1016/j.bios.2016.03.004

Chen, C., Zhang, X., Long, Z., Zhang, J., Zheng, C., 2012. Microchim. Acta 178, 293-299. doi:10.1007/s00604-012-0833-2

Chen, L., Li, B., 2012. Anal. Methods 4, 2613. doi:10.1039/c2ay25354b 
Chen, L., Liu, J., Zeng, Q., Wang, H., Yu, A., Zhang, H., Ding, L., 2009. J. Chromatogr. A 1216, 3710-9. doi:10.1016/j.chroma.2009.02.044

Chen, L., Wang, X., Lu, W., Wu, X., Li, J., 2016. Chem. Soc. Rev. 45. doi:10.1039/C6CS00061D

Chen, L., Xu, S., Li, J., 2011. Chem. Soc. Rev. 40, 2922-2942. doi:10.1039/c0cs00084a

Cieplak, M., Kutner, W., 2016. Trends Biotechnol. 34, 922-941. doi:10.1016/j.tibtech.2016.05.011

Curk, T., Dobnikar, J., Frenkel, D., 2016. Soft Matter 12, 35-44. doi:10.1039/c5sm02144h

Dai, J., Zhang, Y., Pan, M., Kong, L., Wang, S., 2014. J. Agric. Food Chem. 62, 5269-5274. doi:10.1021/jf501092u

Del Carmen Alcudia-León, M., Lucena, R., Cárdenas, S., Valcárcel, M., 2016. J. Chromatogr. A. 1455, 57-64. doi:10.1016/j.chroma.2016.05.088

Deng, J., Ju, S., Liu, Y., Xiao, N., Xie, J., Zhao, H., 2015. Food Anal. Methods 8, $2437-$ 2446. doi:10.1007/s12161-015-0134-6

Díaz-Alvarez, M., Turiel, E., Martín-Esteban, A., 2009. Anal. Bioanal. Chem. 393, 899-905. doi:http://dx.doi.org/10.1016/j.chroma.2013.12.083

Djozan, D., Ebrahimi, B., Mahkam, M., Farajzadeh, M.A., 2010. Anal. Chim. Acta 674, 408. doi:http://dx.doi.org/10.1016/j.aca.2010.06.006

Eren, T., Atar, N., Yola, M.L., Karimi-Maleh, H., 2015. Food Chem. 185, 430-436. doi:10.1016/j.foodchem.2015.03.153

Fang, G., Wang, H., Yang, Y., Liu, G., Wang, S., 2016. Sensors Actuators, B Chem. 237, 239-246. doi:10.1016/j.snb.2016.06.099

Farre, M., Barcelo, D., 2007. Chapter 16 - Sensor, biosensors and MIP based sensors, in: Pico, Y., Food Toxicants Analysis, Elsevier, Amsterdam, 599-636. doi:10.1016/B978044452843-8/50017-1

Feng, S., Hu Y., Ma, L., Lu, X., 2017. Sensors and Actuators, B: Chemical, 241, 750-757. doi: 10.1016/j.snb.2016.10.131

Feng, S., Lu X., 2015. Lipid Technology, 27 , 14-17. doi: 10.1002/lite.201400073

Gao, F., Grant, E., Lu, X., 2015a. Anal. Chim. Acta 901, 68-75. doi:10.1016/j.aca.2015.10.025

Gao, F., Hu, Y., Chen, D., Li-Chan, E.C.Y., Grant, E., Lu, X., 2015b. Talanta 143, 344-352. doi:10.1016/j.talanta.2015.05.003

Gawande, M.B., Goswami, A., Asefa, T., Guo, H., Biradar, A. V, Peng, D., Zboril, R., Varma, R.S., 2015. Chem. Soc. Rev. 44, 7540-7590. doi:10.1039/C5CS00343A

Ge, L., Wang, S., Yu, J., Li, N., Ge, S., Yan, M., 2013. Adv. Funct. Mater. 23, 3115-3123. doi:10.1002/adfm.201202785 
Han, S., Li, X., Wang, Y., Su, C., 2014. Anal. Methods. 6, 2855. doi:10.1039/c3ay41924j

Harz, S., Schimmelpfennig, M., Tse Sum Bui, B., Marchyk, N., Haupt, K., Feller, K.H., 2011. Eng. Life Sci. 11, 559-565. doi:10.1002/elsc.201000222

Hawari, H.F., Samsudin, N.M., Shakaff, A.Y.M., Wahab, Y., Hashim, U., Zakaria, A., Ghani, S.A., Ahmad, M.N., 2013. Sensors Actuators, B Chem. 187, 434-444. doi:10.1016/j.snb.2013.01.045

He, C., Long, Y., Pan, J., Li, K., Liu, F., 2007. J. Biochem. Biophys. Methods 70, 133-50. doi:http://dx.doi.org/10.1016/j.jbbm.2006.07.005

Hoshino, Y., Kodama, T., Okahata, Y., Shea, K.J., 2008. J. Am. Chem. Soc. 130, 1524215243. doi:10.1021/ja8062875

Hu, X., Cai, Q., Fan, Y., Ye, T., Cao, Y., Guo, C., 2012. J. Chromatogr. A 1219, 39-46. doi:http://dx.doi.org/10.1016/j.chroma.2011.10.089

Hu, X., Wu, X., Yang, F., Wang, Q., He, C., Liu, S., 2016. Talanta 148, 29-36. doi:http://dx.doi.org/10.1016/j.talanta.2015.10.057

Hu, Y., Feng, S., Gao, F., Li-Chan, E.C.Y., Grant, E., Lu, X., 2015. Food Chem. 176, 123129. doi:10.1016/j.foodchem.2014.12.051

Hu, Y., Lu, X., 2016. J. Food Sci. 81, N1272-N1280. doi:10.1111/1750-3841.13283

Hu, Y., Wang, Y., Chen, X., Hu, Y., Li, G., 2010. Talanta 80, 2099-105. doi:http://dx.doi.org/10.1016/j.talanta.2009.11.015

Iqbal, N., Mustafa, G., Rehman, A., Biedermann, A., Najafi, B., Lieberzeit, P.A., Dickert, F.L., 2010. Sensors 10, 6361-6376. doi:10.3390/s100706361

Irshad, M., Iqbal, N., Mujahid, A., Afzal, A., Hussain, T., Sharif, A., Ahmad, E., Athar, M., 2013. 3, 615-637. doi:10.3390/nano3040615

Jiang, H., Jiang, D., Shao, J., Sun, X., 2016. Biosens. Bioelectron. 75, 411-419. doi:10.1016/j.bios.2015.07.045

Jing, L., Zhang, Q., Wang, Y., Liu, X., Wei, T., 2016. S Anal. Methods 8, 2349-2356. doi:10.1039/C6AY00028B

Karaseva, N., Ermolaeva, T., Mizaikoff, B., 2016. Sensors Actuators, B Chem. 225, 199-208. doi:10.1016/j.snb.2015.11.045

Khan, M.S., Wate, P.S., Krupadam, R.J., 2012. C J. Mol. Model. 18, 1969-1981. doi:10.1007/s00894-011-1218-x

Khan, S., Bhatia, T., Trivedi, P., Satyanarayana, G.N. V, Mandrah, K., Saxena, P.N., Mudiam, M.K.R., Roy, S.K., 2016. Food Chem. 199, 870-5. doi:http://dx.doi.org/10.1016/j.foodchem.2015.12.091

Koesdjojo, M.T., Rasmussen, H.T., Fermier, A.M., Patel, P., Remcho, V.T., 2007. J. Comb. Chem. 9, 929-934. doi:10.1021/cc0700243

Kryscio, D.R., Shi, Y., Ren, P., Peppas, N.A., 2011. Ind. Eng. Chem. Res. 50, 13877-13884. 
doi:10.1021/ie201858n

Lasáková, M., Jandera, P., 2009. J. Sep. Sci. 32, 799-812. doi:10.1002/jssc.200800506

Lautner, G., Kaev, J., Reut, J., Öpik, A., Rappich, J., Syritski, V., Gyurcsányi, R.E., 2011. Adv. Funct. Mater. 21, 591-597. doi:10.1002/adfm.201001753

Lejeune, J., Spivak, D.A., 2009. Biosens. Bioelectron. 25, 604-8. doi:10.1016/j.bios.2009.02.014

Li, C., Ma, Y., Niu, H., Zhang, H., 2015a. ACS Appl. Mater. Interfaces 7, 27340-27350. doi:10.1021/acsami.5b08868

Li, C., Ma, Y., Niu, H., Zhang, H., 2015b. ACS Appl. Mater. Interfaces 7, 27340-50. doi:10.1021/acsami.5b08868

Li, H., Wang, L., 2013. ACS Appl Mater Interfaces 5, 10502-10509. doi:10.1021/am4020605

Li, H., Guan, H., Dai, H., Tong, Y., Zhao, X., Qi, W., Majeed, S., Xu, G., 2012. Talanta. 99, 811-815. doi:10.1016/j.talanta.2012.07.033

Li, J., Li, Y., Zhang, Y., Wei, G., 2012. Anal. Chem. 84, 1888-1893. doi:10.1021/ac2026817

Li, Y., Li, Y., Huang, L., Bin, Q., Lin, Z., Yang, H., Cai, Z., Chen, G., 2013. J. Mater. Chem. B 1, 1256. doi:10.1039/c2tb00398h

Li, Z., Quan, H., Gong, C., Yang, Y., Tang, Q., Wei, Y., Ma, X., Lam, H., 2015. Food Chem. 172, 56-62. doi:10.1016/j.foodchem.2014.09.027

Lin, C.I., Joseph, A.K., Chang, C.K., Lee, Y. Der, 2004. J. Chromatogr. A 1027, 259-262. doi:10.1016/j.chroma.2003.10.037

Liu, H.L., Fang, G.Z., Li, C.M., Pan, M.F., Liu, C.C., Fan, C., Wang, S., 2012. J. Mater. Chem. 22, 19882-19887. doi:10.1039/c2jm33522k

Liu, X., Lei, J., 2012. Polym. Eng. Sci. 52, 2099-2105. doi:10.1002/pen.23159

Liu, Y., Liu, L., He, Y., He, Q., Ma, H., 2016. Biosens. Bioelectron. 77, 886-893. doi:10.1016/j.bios.2015.10.024

Lu, H., Xu, S., 2015. Talanta 144, 303-11. doi:10.1016/j.talanta.2015.06.017

Lu, W., Xue, M., Xu, Z., Dong, X., Xue, F., Wang, F., Wang, Q., Meng, Z., 2015. Curr. Org. Chem. 19, 62-71. doi:10.2174/1385272819666141201215551

Ma, Y., Pan, G., Zhang, Y., Guo, X., Zhang, H., 2013. J. Mol. Recognit. 26, 240-51. doi:10.1002/jmr.2267

Malitesta, C., Mazzotta, E., Picca, R.A., Poma, A., Chianella, I., Piletsky, S.A., 2012. Anal. Bioanal. Chem. 402, 1827-1846. doi:10.1007/s00216-011-5405-5

Matsui, J., Takayose, M., Akamatsu, K., Nawafune, H., Tamaki, K., Sugimoto, N., 2009. Analyst 134, 80-86. doi:10.1039/b803350a

Muzyka, K., Karim, K., Guerreiro, A., Poma, A., Piletsky, S., 2014. Nanoscale Res. Lett. 9, 
Narsaiah, K., Jha, S.N., Bhardwaj, R., Sharma, R., Kumar, R., 2012. J. Food Sci. Technol. 49, 383-406. doi:10.1007/s13197-011-0437-6

Nicholls, I.A., Chavan, S., Golker, K., Karlsson, B.C.G., Olsson, G.D., Rosengren, A.M., Suriyanarayanan, S., Wiklander, J.G., 2015. Springer International Publishing, pp. 2550. doi:10.1007/10_2015_318

Otles, S., Yalcin, B., 2012. Review on the application of nanobiosensors in food analysis. Acta Sci. Pol. Technol. Aliment. 11, 7-18.

Pardieu, E., Cheap, H., Vedrine, C., Lazerges, M., Lattach, Y., Garnier, F., Remita, S., Pernelle, C., 2009. Anal. Chim. Acta 649, 236-245. doi:10.1016/j.aca.2009.07.029

Peng, H., Wang, S., Zhang, Z., Xiong, H., Li, J., Chen, L., Li, Y., 2012. J. Agric. Food Chem. 60, 1921-1928. doi:10.1021/jf204736p

Pérez-Moral, N., Mayes, A.G., 2007. Macromol. Rapid Commun. 28, 2170-2175. doi:10.1002/marc.200700532

Pozo-Bayón, Pueyo, E., Martín-Alvarez, P.J., Polo, M.C., 2001. J. Chromatogr. A 922, 26775. doi:http://dx.doi.org/10.1016/S0021-9673(01)00966-9

Rodriguez-Lorenzo, L., Fabris, L., Alvarez-Puebla, R.A., 2012. Anal. Chim. Acta 745, 1023. doi:10.1016/j.aca.2012.08.003

Sabik, H., Fortin, J., Martin, N., 2012. Food Chem. 133, 1006-1010. doi:http://dx.doi.org/10.1016/j.foodchem.2011.07.132

Salvador, J.P., Estevez, M.C., Marco, M.P., Sanchez-Baeza, F., 2007. Anal. Lett. 40, 12941306. doi: $10.1080 / 00032710701326668$

Saraji, M., Rezaei, B., Boroujeni, M.K., Bidgoli, A.A.H., 2013. J. Chromatogr. A 1279, 20-6. doi:http://dx.doi.org/10.1016/j.chroma.2013.01.017

Schweitz, L., Andersson, L.I., Nilsson, S., 2002. Analyst 127, 22-8. doi:10.1039/B105104K

Sharma, P.S., Pietrzyk-Le, A., D’Souza, F., Kutner, W., 2012. Anal. Bioanal. Chem. 402, 3177-3204. doi:10.1007/s00216-011-5696-6

Sigma-Aldrich, 2016. SupelMIP Molecularly Imprinted Polymer SPE Cartridges [WWW Document]. URL http://www.sigmaaldrich.com/analytical-chromatography/samplepreparation/spe/supelmip.html

Song, X., Xu, S., Chen, L., Wei, Y., Xiong, H., 2014. J. Appl. Polym. Sci. 131, 40766. doi:10.1002/app.40766

Sorouraddin, S.M., Afshar Mogaddam, M.R., 2016. J. Iran. Chem. Soc. 13, 1093-1104. doi:10.1007/s13738-016-0823-0

Suryanarayanan, V., Wu, C.-T., Ho, K.-C., 2010. Electroanalysis 22, 1795-1811. doi:10.1002/elan.200900616

The Huy, B., Seo, M.H., Zhang, X., Lee, Y.I., 2014. Biosens. Bioelectron. 57, 310-316. 
doi:10.1016/j.bios.2014.02.041

Toshifumi Takeuchi, Daigo Fukuma, A., Matsui, J., 1998. Anal. Chem. 71, 285-290. doi:10.1021/AC980858V

Turco, A., Corvaglia, S., Mazzotta, E., 2015. Biosens. Bioelectron. 63, 240-247. doi:10.1016/j.bios.2014.07.045

Turiel, E., Martín-Esteban, A., Carro-Diaz, A.M., Lorenzo-Ferreira, R.A., 2010. Anal. Chim. Acta 668, 87-99. doi:10.1016/j.aca.2010.04.019

Uzun, L., Turner, A.P.F., 2016. Biosens. Bioelectron. 76, 131-144. doi:10.1016/j.bios.2015.07.013

Uzuriaga-Sánchez, R.J., Khan, S., Wong, A., Picasso, G., Pividori, M.I., Sotomayor, M.D.P.T., 2016. Food Chem. 190, 460-467. doi:10.1016/j.foodchem.2015.05.129

Vaihinger, D., Landfester, K., Kra, I., Brunner, H., Günter E. M. Tovar, 2002. Macromol. Chem. Phys. 203, 1965-1973. doi:10.1002/1521-3935(200209)203:13<1965::AIDMACP1965>3.0.CO;2-C

Vas, G., Vékey, K., 2004. J. Mass Spectrom. 39, 233-54. doi:10.1002/jms.606

Wackerlig, J., Lieberzeit, P.A., 2015. Sensors Actuators B Chem. 207, 144-157. doi:10.1016/j.snb.2014.09.094

Wang, A., Lu, H., Xu, S., 2016. 64, 5110-5116. doi:10.1021/acs.jafc.6b01197

Wang, H., Yao, S., Liu, Y., Wei, S., Su, J., Hu, G., 2017. M Biosens. Bioelectron. 87, 417421. doi:10.1016/j.bios.2016.08.092

Wang, X., Kang, Q., Shen, D., Zhang, Z., Li, J., Chen, L., 2014. Talanta 124, 7-13. doi:10.1016/j.talanta.2014.02.040

Wang, X., Tang, Q., Wang, Q., Qiao, X., Xu, Z., 2014. J. Sci. Food Agric. 94, 1409-15. doi:10.1002/jsfa.6429

Wang, Y.-L., Gao, Y.-L., Wang, P.-P., Shang, H., Pan, S.-Y., Li, X.-J., 2013. Talanta 115, 920-7. doi:10.1016/j.talanta.2013.06.056

Wei, S., Liu, Y., Yan, Z., Liu, L., 2015. RSC Adv. 5, 20951-20960. doi:10.1039/C4RA16784H

Weng, C.H., Yeh, W.M., Ho, K.C., Lee, G. Bin, 2007. Sensors Actuators, B Chem. 121, 576582. doi:10.1016/j.snb.2006.04.111

Xu, C.-H., Chen, G.-S., Xiong, Z.-H., Fan, Y.-X., Wang, X.-C., Liu, Y., 2016. TrAC Trends Anal. Chem. 80, 12-29. doi:10.1016/j.trac.2016.02.022

Xu, J., Ambrosini, S., Tamahkar, E., Rossi, C., Haupt, K., Bui, B.T.S., 2015. Biomacromolecules 17, 345-353. doi:10.1021/acs.biomac.5b01454

Xu, Z., Fang, G., Wang, S., 2010. Food Chem. 119, 845-850. doi:http://dx.doi.org/10.1016/j.foodchem.2009.08.047 
Xue, J.Q., Li, D.W., Qu, L.L., Long, Y.T., 2013. Anal. Chim. Acta 777, 57-62. doi:10.1016/j.aca.2013.03.037

Yang, L., Yang, J., Xu, B., Zhao, F., Zeng, B., 2016. Talanta 161, 413-418. doi:10.1016/j.talanta.2016.08.080

Yao, G., Liang, R., Huang, C., Wang, Y., Qiu, J., 2013. Anal. Chem. 85, 11944-51. doi:10.1021/ac402848x

Yao, T., Gu, X., Li, T., Li, J., Li, J., Zhao, Z., Wang, J., Qin, Y., She, Y., 2016. Biosens. Bioelectron. 75, 96-100. doi:10.1016/j.bios.2015.08.027

Ye, L., Cormack, P.A.G., Mosbach, K., 1999. Anal. Commun. 36, 35-38. doi:10.1039/a809014i

Yu, D., Zeng, Y., Qi, Y., Zhou, T., Shi, G., 2012. Biosens. Bioelectron. 38, 270-277. doi:10.1016/j.bios.2012.05.045

Zhang, J., Ni, Y., Wang, L., Ma, J., Zhang, Z., 2015. Biomed. Chromatogr. 29, 1267-73. doi:http://dx.doi.org/10.1016/j.foodchem.2009.08.047

Zhang, M., Zeng, J., Wang, Y., Chen, X., 2013. J. Chromatogr. Sci. 51, 577-86. doi:10.1093/chromsci/bms260

Zhao, H., Wang, H., Quan, X., Tan, F., 2013 Procedia. Environ. Sci. 18, 249-257. doi:10.1016/j.proenv.2013.04.032

Zhao, N., Chen, C., zhou, J., 2012. Sensors Actuators B Chem. 166, 473-479. doi:10.1016/j.snb.2012.02.089

Zhao, T., Guan, X., Tang, W., Ma, Y., Zhang, H., 2015. Anal. Chim. Acta 853, 668-75. doi:10.1016/j.aca.2014.10.019

Zhao, Y., Ma, Y., Li, H., Wang, L., 2012. Anal. Chem. 84, 386-395. doi:10.1021/ac202735v 


\section{Figure Captions}

Figure 1. Overview of MIP imprinting.

Figure 2. Schematic representation of the preparation of magnetic molecular imprinted polymer. (1) Synthesis of magnetic core particle; (2) Silanization by tetraethoxy silane (TEOS); (3) Surface modification with 3-N-morpholinopropanesulfonic acid (MOPS); (4) Encapsulation and polymerization of MIP layer; (5) Template removal.

Figure 3. Schematic representation of integration of MIPs in various types of biosensors. (Adapted from Lu et al., 2015).

\section{Table Captions}

Table 1. Summary of the applications of MIP-SPE and MIP-SPME in food analysis.

Table 2. Summary of the applications of MIPs as biosensor receptors. 


\section{Figures}

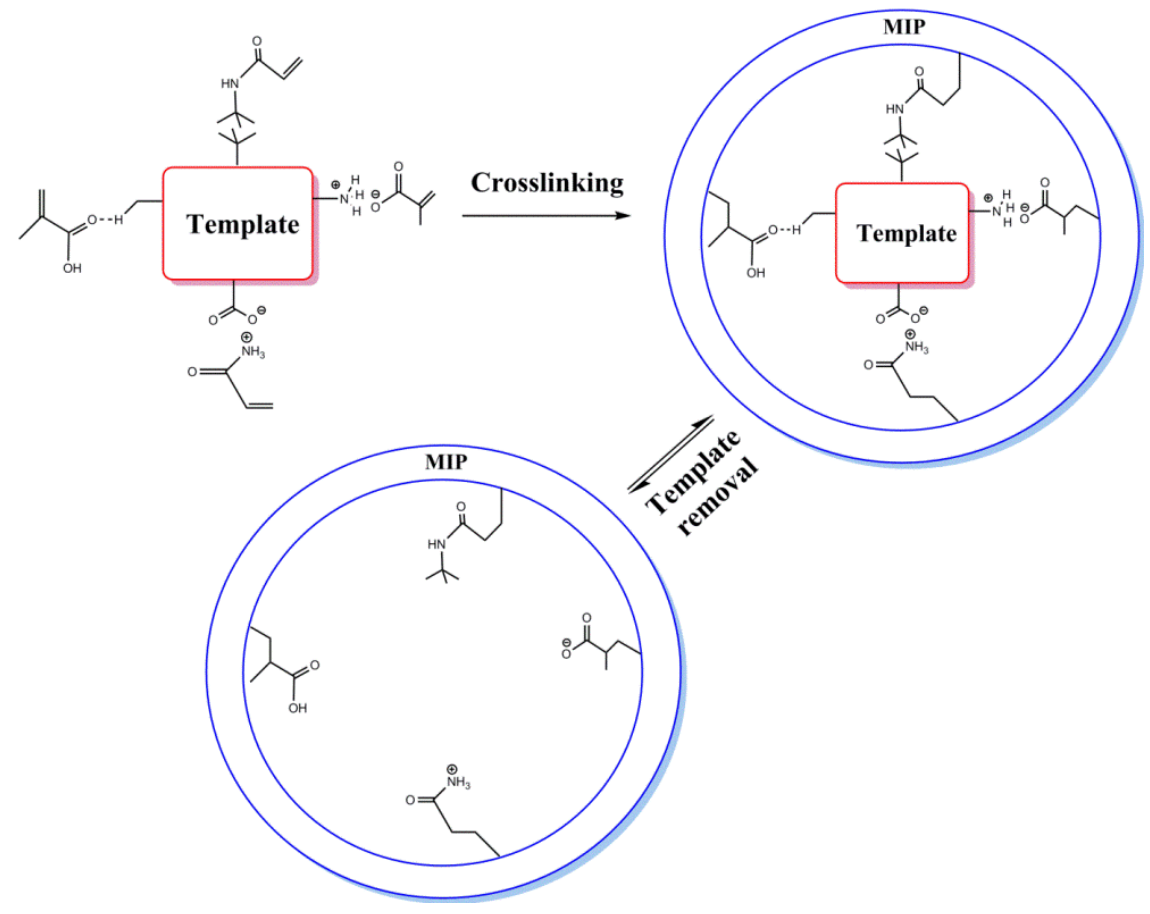

Figure 1 


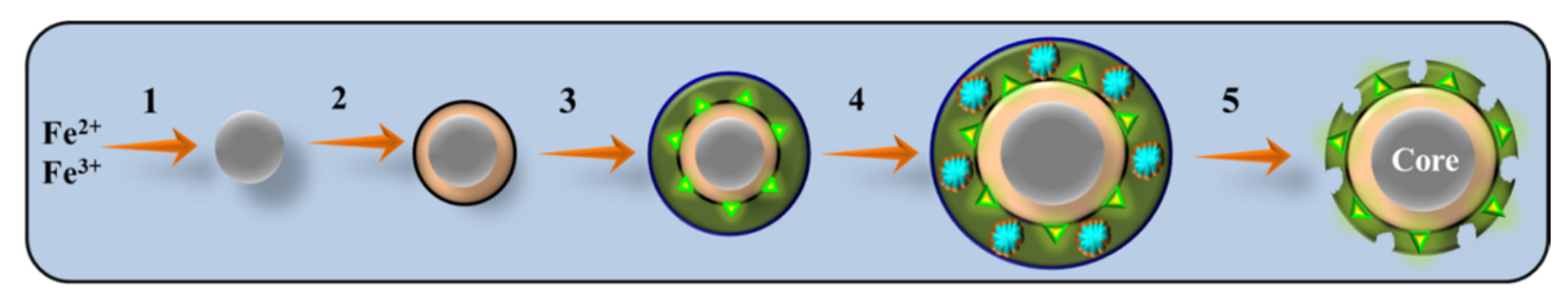

Figure 2 


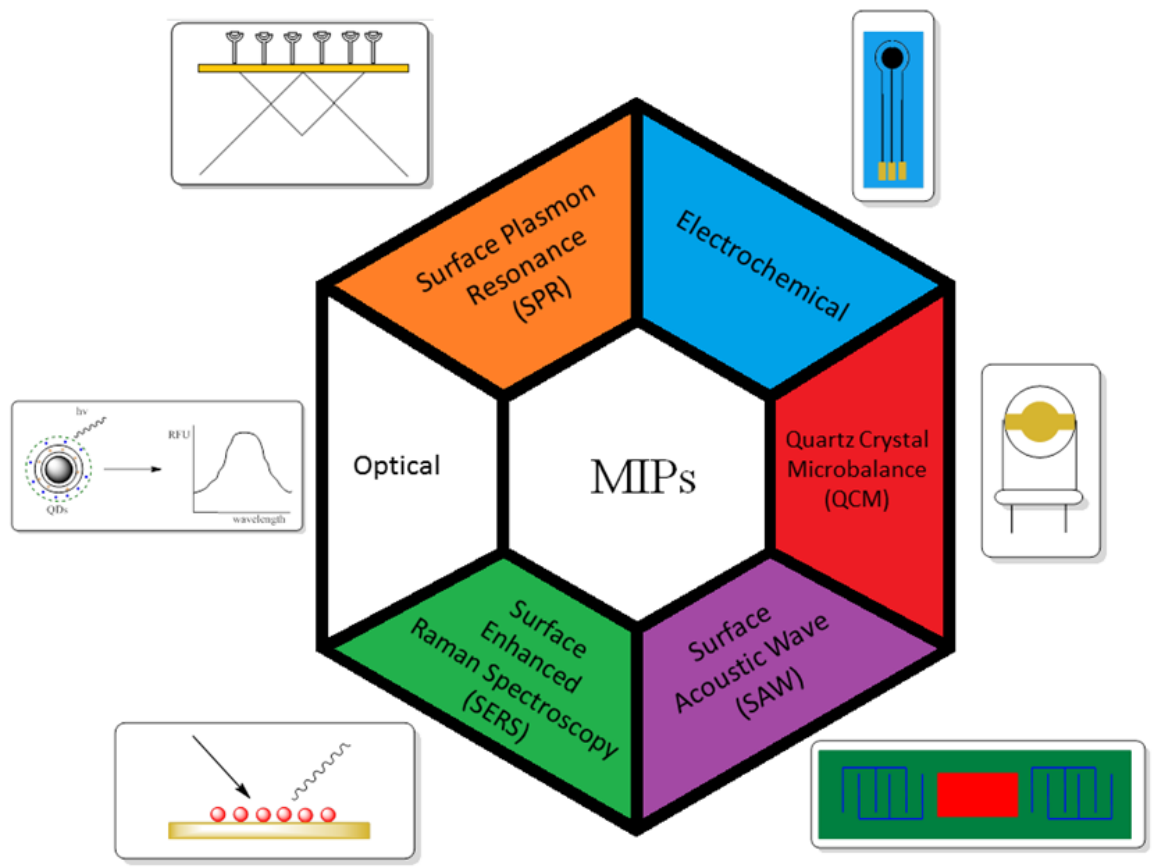

Figure 3. 


\section{Tables}

Table 1.

\begin{tabular}{|c|c|c|c|c|c|}
\hline Analyte & $\begin{array}{l}\text { Preparation } \\
\text { method }\end{array}$ & sample & LOD & Recovery & Reference \\
\hline $\mathrm{E} 1$, betaE2, E3 & Sol-gel reaction & Water & $\begin{array}{l}86-430 \mathrm{ng} \\
\mathrm{L}^{-1}\end{array}$ & $85-95 \%$ & (Lu and $\mathrm{Xu}, 2015)$ \\
\hline Estradiol & $\begin{array}{l}\text { Copolymerization } \\
\text { of monomers on } \\
\text { hollow particles }\end{array}$ & milk & $\begin{array}{ll}4600 & \text { ng } \\
L^{-1} & \end{array}$ & $94.8-97 \%$ & $\begin{array}{l}\text { (Xiaoyan Wang et al., } \\
\text { 2014) }\end{array}$ \\
\hline Triazines & $\begin{array}{l}\text { Thermal } \\
\text { polymerization of } \\
\text { microparticles }\end{array}$ & Grape juice & $\begin{array}{ll}0.2-7 & \text { ng } \\
\mathrm{mL}^{-1} & \end{array}$ & $92-98 \%$ & $\begin{array}{l}\text { (Sorouraddin and } \\
\text { Afshar Mogaddam, } \\
\text { 2016) }\end{array}$ \\
\hline Patulin & $\begin{array}{l}\text { Polymerization on } \\
\text { the substrate }\end{array}$ & apple juice & $8.6 \mu \mathrm{g} \mathrm{L}^{-1}$ & $82-98 \%$ & (Anene et al., 2016) \\
\hline Bisphenol A & Hybrid imprinting & Water & $\begin{array}{ll}0.3 & \mathrm{ng} \\
\mathrm{mL}^{-1} & \end{array}$ & $97.3-106.0 \%$ & (Hu et al., 2016) \\
\hline Dichlorovos & $\begin{array}{l}\text { thermal-initiated } \\
\text { polymerization }\end{array}$ & $\begin{array}{l}\text { Cucumber, } \\
\text { lettuce }\end{array}$ & $\begin{array}{ll}94.8 & \text { ng } \\
\mathrm{L}^{-1} & \end{array}$ & $82.1-94.0 \%$ & (Xu et al., 2010) \\
\hline Aflatoxin B1 & Emulsification & $\begin{array}{l}\text { Beer, } \\
\text { peanut oil }\end{array}$ & $\begin{array}{l}0.05 \\
\mathrm{~kg}^{-1}\end{array} \quad \mu \mathrm{g}$ & $83-96 \%$ & (Wei et al., 2015) \\
\hline Guanine & $\begin{array}{l}\text { Thermal } \\
\text { polymerization }\end{array}$ & Beer & ---- & Above $97 \%$ & (Z. Li et al., 2015) \\
\hline Fenarimol & $\begin{array}{l}\text { precipitation } \\
\text { polymerization }\end{array}$ & Fruit & $\begin{array}{l}0.03-0.06 \\
\mu \mathrm{g} \mathrm{mL}^{-1}\end{array}$ & $\begin{array}{l}91.16- \\
99.52 \%\end{array}$ & (Khan et al., 2016) \\
\hline Trichlorfon & $\begin{array}{l}\text { precipitation } \\
\text { polymerization }\end{array}$ & Vegetables & $4.2 \mu \mathrm{g} \mathrm{g}^{-1}$ & $88.5-94.2 \%$. & $\begin{array}{l}\text { (Xilong Wang et al., } \\
\text { 2014) }\end{array}$ \\
\hline $\begin{array}{l}\text { Organophosphorus } \\
\text { pesticides }\end{array}$ & $\begin{array}{l}\text { electrochemical } \\
\text { deposition }\end{array}$ & $\begin{array}{l}\text { Water, } \\
\text { cucumber, } \\
\text { lettuce }\end{array}$ & $\begin{array}{l}1.5-10 \mathrm{ng} \\
\mathrm{L}^{-1}\end{array}$ & $80-109 \%$ & (Saraji et al., 2013) \\
\hline Sulfamethazine & $\begin{array}{l}\text { Thermal } \\
\text { polymerization }\end{array}$ & milk & $1.1 \mu \mathrm{g} \mathrm{L}^{-1}$ & $89-110 \%$ & (Chen et al., 2012) \\
\hline 17beta-estradiol & $\begin{array}{l}\text { Thermal } \\
\text { polymerization on } \\
\text { silica fiber }\end{array}$ & $\begin{array}{ll}\text { fish and } \\
\text { shrimp }\end{array}$ & $\begin{array}{l}0.98- \\
2.39 \mu \mathrm{g} \\
\mathrm{L}^{-1}\end{array}$ & Above $80 \%$ & (Hu et al., 2010) \\
\hline Triazinez & $\begin{array}{l}\text { Photochemical } \\
\text { polymerization }\end{array}$ & $\begin{array}{l}\text { Water, rice, } \\
\text { onion }\end{array}$ & $\begin{array}{lr}\text { Less } & \text { than } \\
85 & \text { ng } \\
\mathrm{mL}^{-1} & \end{array}$ & Above $85 \%$ & (Djozan et al., 2010) \\
\hline
\end{tabular}


Table 2.

\begin{tabular}{|c|c|c|c|c|c|}
\hline $\begin{array}{l}\text { Biosensor } \\
\text { transducer }\end{array}$ & Analyte & $\begin{array}{l}\text { Food } \\
\text { sample }\end{array}$ & $\begin{array}{l}\text { Sensor surface } \\
\text { preparation } \\
\text { method }\end{array}$ & LOD & Reference \\
\hline $\mathrm{QCM}$ & Patulin & $\begin{array}{l}\text { Apple juice, } \\
\text { pear juice } \\
\text { and } \\
\text { Haw Flakes }\end{array}$ & $\begin{array}{l}\text { TEOS } \\
\text { imprinting }\end{array}$ & $3.1 \mathrm{ng} \mathrm{ml}^{-1}$ & $\begin{array}{l}\text { (Fang et al., } \\
\text { 2016) }\end{array}$ \\
\hline QCM & $\begin{array}{l}\text { Penicillin G, } \\
\text { ampicillin }\end{array}$ & $\begin{array}{l}\text { Chicken } \\
\text { meat }\end{array}$ & $\begin{array}{l}\text { Suspension } \\
\text { polymerization }\end{array}$ & $\begin{array}{l}0.04,0.09 \mu \mathrm{g} \\
\mathrm{ml}^{-1}\end{array}$ & $\begin{array}{l}\text { (Karaseva et } \\
\text { al., 2016) }\end{array}$ \\
\hline SPR & Ractopamine & n.d & $\begin{array}{l}\text { Hybrid } \\
\text { nanofilm of } \\
\text { MIP/gold } \\
\text { nanoparticles } \\
\text { and reduced } \\
\text { graphene oxide }\end{array}$ & $5 \mathrm{ng} \mathrm{ml}^{-1}$ & $\begin{array}{l}\text { (Yao et al., } \\
2016)\end{array}$ \\
\hline $\begin{array}{l}\text { Electrochemical } \\
\text { (CV) }\end{array}$ & Olaquindox & $\begin{array}{l}\text { Pork and } \\
\text { Fish }\end{array}$ & $\begin{array}{l}\text { Electrochemical } \\
\text { imprinting }\end{array}$ & $2.7 \mathrm{nM}$ & $\begin{array}{l}\text { (Wang et al., } \\
\text { 2017) }\end{array}$ \\
\hline $\begin{array}{l}\text { Electrochemical } \\
\text { (DPV) }\end{array}$ & $\begin{array}{l}\text { N-acyl-homoserine- } \\
\text { lactones }\end{array}$ & n.d & $\begin{array}{l}\text { Core-shell } \\
\text { imprinting }\end{array}$ & $0.8 \mathrm{nmol} \mathrm{L}^{-1}$ & $\begin{array}{l}\text { (Jiang et al., } \\
\text { 2016) }\end{array}$ \\
\hline $\begin{array}{l}\text { Electrochemical } \\
\text { (CV and DPV) }\end{array}$ & Oxytetracycline & milk & $\begin{array}{l}\text { Electrochemical } \\
\text { imprinting }\end{array}$ & $230 \mathrm{fmol} \mathrm{L}^{-1}$ & $\begin{array}{l}\text { (Li et al., } \\
\text { 2012) }\end{array}$ \\
\hline SERS & Melamine & Whole milk & $\begin{array}{l}\text { Bulk } \\
\text { polymerisation }\end{array}$ & $12 \mu \mathrm{mol}^{-1}$ & $\begin{array}{l}\text { (Hu et al., } \\
2015)\end{array}$ \\
\hline Fluorescence & $\begin{array}{l}\text { Melamine and } \\
\text { clenbuterol }\end{array}$ & $\begin{array}{l}\text { Milk and } \\
\text { liver }\end{array}$ & $\begin{array}{l}\text { Core-shell } \\
\text { imprinting }\end{array}$ & $\begin{array}{l}0.4 \mu \mathrm{mol} \mathrm{L}^{-1} \\
\text { and } 0.6 \mu \mathrm{mol} \\
\mathrm{L}^{-1}\end{array}$ & $\begin{array}{l}\text { (The Huy et } \\
\text { al., 2014) }\end{array}$ \\
\hline Fluorescence & $\begin{array}{l}\text { Polycyclic aromatic } \\
\text { hydrocarbons }\end{array}$ & Milk & $\begin{array}{l}\text { Core-shell } \\
\text { imprinting }\end{array}$ & $3.64 \mathrm{ng} \mathrm{ml}^{-1}$ & $\begin{array}{l}\text { (Li and Wang, } \\
\text { 2013) }\end{array}$ \\
\hline
\end{tabular}

Quartz Crystal Microbalance (QCM), Surface Plasmon Resonance (SPR), Differential Pulse Voltammetry (DPV), Cyclic Voltammetry (CV), Surface Enhanced Raman Spectroscopy (SERS) 